\title{
Clinical approach to obscure GI bleeding - Diagnostic testing and management
}

\author{
Prashanth Prabakaran ${ }^{1}$, Nalini Guda ${ }^{2}$, Jacob Thomas ${ }^{3}$, Charles Heise ${ }^{4}$, Deepak Gopal ${ }^{1,5}$ \\ ${ }^{1}$ Division of Gastroenterology \& Hepatology, ${ }^{3}$ Departments of Radiology and Diagnostic Imaging, ${ }^{4}$ General Surgery, ${ }^{5}$ Medicine, University of \\ Wisconsin - School of Medicine \& Public Health Suite 4000, 1685 Highland Ave, Madison, Wisconsin, USA, ${ }^{2}$ Division of Gastroenterology \& \\ Hepatology University of Wisconsin GI Associates, St. Luke's Medical Center Milwaukee, Wisconsin, USA
}

\begin{abstract}
Obscure gastrointestinal bleeding (OGIB) can present as a diagnostic dilemma and management can be challenging. The search for causes of OGIB is usually centered on visualizing the small bowel, and in the past decade, the technology to visualize the entire small bowel has significantly advanced. Moreover, small bowel endoscopic imaging has replaced, in many instances, prior radiographic evaluation for obscure GI bleeding. These new modalities, such as small bowel capsule endoscopy (CE), balloon-assisted deep enteroscopy [double balloon enteroscopy (DBE) and single balloon enteroscopy (SBE)], and overtube-assisted deep enteroscopy (spiral enteroscopy), are paving the way toward more accurately identifying and treating patients with OGIB. We will review the diagnostic modalities available in evaluating a patient with OGIB and also propose the management based on clinical and endoscopic findings.

Key words Balloon-assisted enteroscopy, deep enteroscopy, magnetic resonance/computed tomography enterography, obscure gastrointestinal bleeding, small bowel capsule endoscopy
\end{abstract}

\section{Introduction}

Obscure gastrointestinal bleeding (OGIB) is characterized by continuous or recurrent bleeding originating in the gastrointestinal (GI) tract after both upper and lower endoscopies yield no evidence of a source. ${ }^{[1,2]}$ This can be further specified as obscure overt bleeding in which patients show clinical signs of active bleeding (e.g. hematochezia, hematemesis, and/or melena) or obscure occult bleeding which entails a patient testing positive on a fecal occult blood test (FOBT) or having refractory iron-deficient anemia. ${ }^{[1-4]}$ Overall, OGIB makes up for $5 \%$ of all reported GI bleed cases. ${ }^{[1,2,5]}$

The search for causes of OGIB are usually centered around visualizing the small bowel, even though in some cases,

\begin{tabular}{|l|c|}
\hline \multicolumn{2}{|c|}{ Access this article online } \\
\hline \multirow{2}{*}{$\begin{array}{l}\text { Website: } \\
\text { www.jdeonline.in }\end{array}$} & Quick Response Code \\
\hline DOI: & \\
10.4103/0976-5042.129966 & \\
\hline
\end{tabular}

the actual cause may be from missed lesions in the upper or lower GI tract during previous evaluation. Repeating an esophagogastroduodenoscopy (EGD) or colonoscopy for these missed lesions is an important step in evaluating OGIB. In the past decade, however, the technology to visualize the small bowel has advanced greatly, and previous methods are usually only used on a case-by-case basis. Moreover, small bowel endoscopic imaging has replaced, in many instances, prior radiographic evaluation for obscure GI bleeding. ${ }^{[1]}$ These new modalities, such as small bowel capsule endoscopy (CE), balloon-assisted deep enteroscopy [double balloon enteroscopy (DBE) and single balloon enteroscopy (SBE)], and overtubeassisted deep enteroscopy (spiral enteroscopy), are paving the way toward more accurately identifying and treating patients with OGIB. We will review the diagnostic modalities available in evaluating a patient with OGIB and also propose management based on clinical and endoscopic findings.

\section{Small Bowel Radiographic Imaging}

Small bowel series/small bowel enteroclysis/CT and MRI enterography

In recent years, small bowel series (SBS) and conventional enteroclysis have become less of broad-spectrum diagnostic

Address for correspondence:

Prof. Deepak V. Gopal, MD, FRCP(C), FACP, AGAF, FACG, FASGE. Department of Medicine, Division of Gastroenterology and Hepatology, University of Wisconsin School of Medicine and Public Health, Suite 4000 UWMF Centennial Bldg, 1685 Highland Avenue, Madison, W1 53705-2281, USA. E-mail: dvg@medicine.wisc.edu 
tools in OGIB. ${ }^{[6]}$ However, SBS may be useful in selected patients with known or suspected Crohn's or nonsteroidal anti-inflammatory drug (NSAID) ulcers. ${ }^{[6,7]}$ SBS is a procedure in which the patient is provided a large quantity of positive contrast orally and then X-ray images of the patient are taken as the contrast moves through the small bowel. Enteroclysis, on the other hand, employs the use of a tube that is put through the nose into the proximal duodenum through which barium, methylcellulose, and air are injected. ${ }^{[2]}$ This method takes fluoroscopic images in real time as the barium flows through the small intestine aided by air and methylcellulose.

One of the reasons that these imaging techniques are falling out of use is the extremely low diagnostic yield of the two (0$5.6 \%$ for SBS and $8 \%$ for enteroclysis following negative push enteroscopy (PE). ${ }^{[2]}$ Another major flaw of these radiographic studies is the inability to detect angioectasias, which are the most common cause of bleeding in the small bowel. ${ }^{[7,8]}$ These two modalities are quickly being replaced by computed tomography (CT) enterography/enteroclysis protocols, both of which offer higher diagnostic yields, but remain in use due to their easy accessibility. ${ }^{[6,9]}$

CT enterography involves the ingestion of a neutral contrast solution, such as polyethelene glycol, which also distends the bowel. ${ }^{[10]}$ In a similar fashion, CT enteroclysis introduces contrast into the small bowel via a nasojejunal tube. Glucagon, an antispasmolytic agent, is often administered to reduce bowel peristalsis and increase distension. ${ }^{[10]}$ Additionally, each procedure requires bowel preparation with a low-residue diet, fluids, and cathartic agent. ${ }^{[1]}$ Subsequently, the patient undergoes multiphase CT scanning, such as arterial, enteric, and delayed phases. Arterial phase scans are most useful for demonstrating vascular lesions, while the enteric phase is better at evaluating neoplastic lesions. ${ }^{[10,12]}$ Active bleeding is best seen on delayed phase as luminal contrast extravasation. Advantages of this technique are the short scan time, non-invasive nature (enteroclysis is slightly more invasive), and ready accessibility in a wide range of centers. However, both these procedures have the disadvantage of exposing the patient to relatively high amounts of radiation, although biphasic or single-phase imaging protocols may be used, especially in young patients. ${ }^{[13]}$ Nevertheless, most patients are older and the bleeding is usually more life threatening than the dose of radiation.

A recent study demonstrated that by using a bolus-tracking, multiphase 64-section CT enterography imaging protocol, vascular lesions, such as angiodysplasias of the small bowel, that can be a source for obscure GI bleeding were detected in a group of outpatients being evaluated. ${ }^{[10,12]}$ In this retrospective study, 22 outpatients with OGIB underwent CT enterography and findings were compared with capsule and traditional endoscopic, surgical, and angiographic findings. CT enterography demonstrated a positive source of obscure GI bleeding in 10 of 22 patients (45\%). Eight of 10 positive findings demonstrated at CT enterography were also noted on small bowel CE. Furthermore, CT enterography correctly identified three lesions undetected at small bowel CE. Several studies have evaluated the relative diagnostic yields of CT enterography and $\mathrm{CE}$ with a wide range of reported values (34-66\% and $33-78 \%$, respectively), but each seems to agree that $\mathrm{CE}$ is superior for detection of shallow mucosal lesions and certain vascular lesions, while CT may be more effective at demonstrating bowel neoplasms. ${ }^{[10,12,13-15]}$ Additionally, CT may provide anatomic localization for lesions to aid with surgical planning. This suggests that CT enterography and CE may play complementary roles in the diagnosis of obscure GI bleeding.

Similar to CT enterography and CT enteroclysis, magnetic resonance (MR) techniques have been developed which parallel those protocols. These sequences also primarily depend on adequate bowel distention with oral contrast agents, which may be negative, positive, or biphasic. ${ }^{[16]}$ One unique capability is the demonstration of bowel function using dynamic MR imaging to create a cine clip of bowel peristalsis. MR enterography and MR enteroclysis are primarily studied in the realm of Crohn's disease, but emerging data suggest a role in the investigation of obscure GI bleeding, particularly when small bowel neoplasm is suspected. There are limited data on diagnostic yield for obscure GI bleeding, with one study suggesting lower sensitivity than CT techniques. ${ }^{[17]}$ This is likely related to the lower spatial and temporal resolution of MR enterography compared to CT enterography at this time. ${ }^{[18]}$ However, this may change with future advances in MR imaging.

\section{Bleeding scan/angiography}

Bleeding scans involve the tagging of autologous erythrocytes with the metastable isotope of technetium-99m (99mTc) and then reinjecting the cells into the patient. ${ }^{[19]}$ The body is then imaged with a gamma camera to examine whether these tagged cells are being deposited into the GI tract via a bleed. Such procedures can detect both arterial and venous bleeding and are minimally invasive to the patient. ${ }^{[6]}$ An advantage of this technique is the ability to detect blood flow rates as low as $0.04 \mathrm{ml} / \mathrm{min}$, meaning that even small lesions will not be overlooked. ${ }^{[20]}$ On the contrary, the overall effectiveness of these scans to localize a site of bleeding has been reported to be less. ${ }^{[19]}$ The statistical data that shows this clearly is the fact that it has a $22 \%$ false-positive rate, which makes it hard to consider as a powerful diagnostic tool. ${ }^{[40]}$ In clinical use, tagged RBC scans are primarily used in the diagnosis of acute, overt bleeding for the purpose of guiding surgical and/or angiographic treatment. ${ }^{[22]}$ Additionally, 99mTc pertechnetate scans can be helpful for the diagnosis of ectopic gastric mucosa in a Meckel's diverticulum, particularly in the pediatric population. ${ }^{[22]}$

Angiography allows for the accurate localization of bleeding if the rate is above $0.5 \mathrm{ml} / \mathrm{min} .{ }^{[23]}$ Not only can bleeding sites be found directly through the injected contrast, but through interpreting different vascular patterns, other lesions such as angioectasias and tumors can also be identified. ${ }^{[6]}$ After identification of such issues, a great advantage of this modality is the ability to directly treat the issues through embolization. ${ }^{[1]}$ In contrast to bleeding scans, angiography 
is an invasive procedure used primarily in the setting of acute overt bleeding, when endoscopic techniques may be limited due to blood or when other diagnostic modalities have been exhausted.

\section{Small Bowel Endoscopic Imaging}

\section{Small bowel CE}

Throughout the history of endoscopy, the challenge of finding a non-invasive technology to visualize the entire small intestine proved to be quite elusive. In the past decade, wireless $\mathrm{CE}$ became the answer to this lingering question [Figure 1]. This revolutionary technology provides a safe and sensitive method for managing patients with OGIB (66\% of CE is used for this) and other issues in the small bowel. ${ }^{[24]}$ It was originally approved in 2000 , and since then, there have been many studies to test its efficacy, diagnostic capabilities, and overall quality as an endoscopic tool. Many studies have shown that the diagnostic capability of CE with respect to OGIB is $60.5 \%{ }^{[6]}$ and it is more effective with overt bleeding versus obscure occult bleeding. ${ }^{[6,25,26]}$ The most common diagnosis made with CE is angiodysplasia (50\%), followed by ulcers $(26.8 \%)$ [Figure 2] and neoplastic lesions (8.8\%) [Figure 3]. ${ }^{[24]}$ It was also noted the diagnostic yield of $\mathrm{CE}$ was highest when done within 2 weeks of a bleeding episode. ${ }^{[27,28]}$

Many studies have shown that CE is far superior to PE and radiographic imaging. A meta-analysis of 14 studies showed that the detection yield for $\mathrm{CE}$ was $63 \%$, which is far greater than that of both $\mathrm{PE}$ and radiographic studies (26\% and $8 \%$, respectively). ${ }^{[7,29]}$ Another study comparing CE to upper GI series with small bowel follow-through indicated $45 \%$ diagnostic yield for $\mathrm{CE}$, while the radiographic imaging trailed with only a $20 \%$ yield. ${ }^{[30]}$ The same study also reported that $\mathrm{CE}$ was much more sensitive for OGIB than barium studies (31 vs. 5\%, respectively). There is, however, a distinct advantage of using $\mathrm{CE}$ before $\mathrm{PE}$; patients who followed this track reduced their need for PE to $25 \%$. ${ }^{[31]}$

Another important use of CE is in the diagnosis of patients with suspected Crohn's disease. If a patient already has active Crohn's, CE can show how they are responding to the therapy regimen they have been put on. ${ }^{[32]} \mathrm{CE}$ has been shown to have a detection rate of about $55 \%$ in those who are suspected to have the disease. ${ }^{[33]}$ This value is comparable to the yield for colonoscopy (48\%) and much better than those of radiography, $\mathrm{PE}$, and $\mathrm{CT}$ enterography/enteroclysis $(22 \%$, $8 \%$, and $31 \%$, respectively). ${ }^{[34]}$ With such strong evidence, it is clear that $\mathrm{CE}$, although a new modality, is on the rise as a powerful diagnostic tool for Crohn's disease. CE can also be used to monitor response to therapy, especially mucosal healing in Crohn's disease.

Limitations of $\mathrm{CE}$ include the inability to provide direct therapy, inability to localize a lesion in the small intestine, erratic passage of the capsule through the small bowel resulting in missed lesions, and also, it is not recommended for use in patients with pacemakers. ${ }^{[35]}$ Despite initial concerns regarding

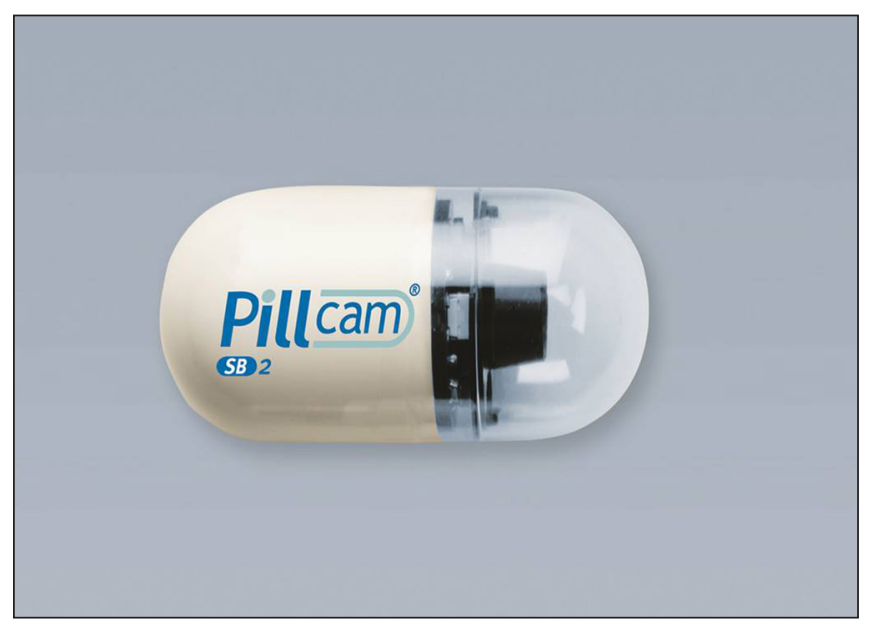

Figure 1: Image of small bowel capsule endoscope - PillCAM (Image courtesy of Given Imaging Ltd; PillCAM and RAPID are trademarks of Given Imaging Ltd)

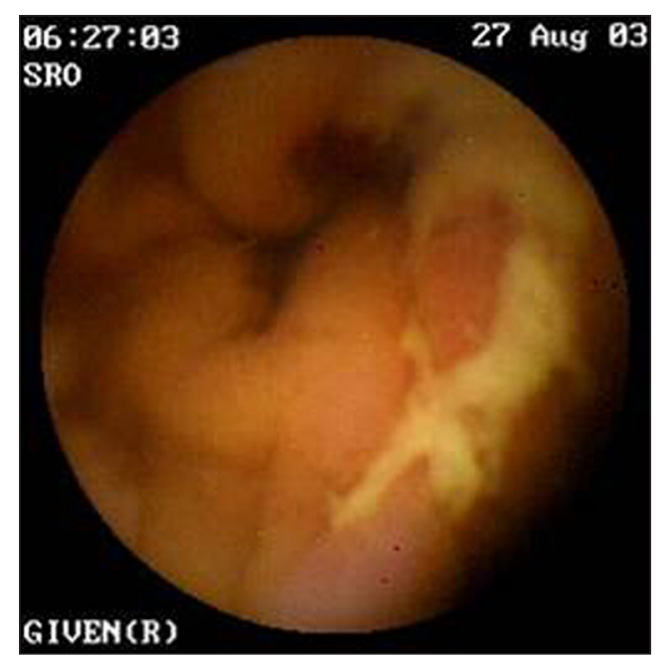

Figure 2: Small bowel capsule image of NSAID-induced ulcers in a 44-year-old female patient undergoing capsule endoscopy exam, after negative upper endoscopy and colonoscopy, for obscure overt GI bleeding

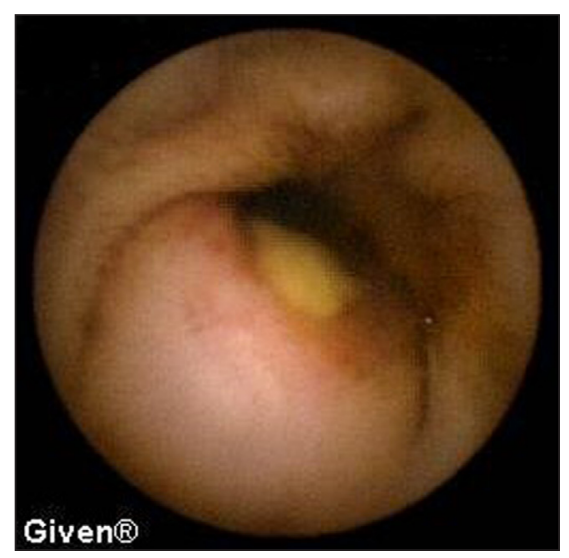

Figure 3: Small bowel capsule image of an ulcerated submucosal lesion detected in a 63-year-old male patient undergoing small bowel capsule endoscopy for obscure, overt GI bleeding. This lesion, localized in the region of the proximal ileum, was removed surgically and diagnosed as an ileal gastrointestinal stromal tumor (GIST) 
the safety of capsule enteroscopy in those with pacemakers and defibrillators, there is growing evidence that it is safe to perform capsule enteroscopy in the presence of these devices. ${ }^{[36]}$

However, the primary concern while using CE is the risk of retaining a capsule. This may be caused by strictures, NSAID use, or previous abdominal surgeries. ${ }^{[1]}$ Katsinelos et al., found in a study that only $2 / 101$ patients $(1.98 \%)$ retained capsules due to neoplasms and required surgical intervention to remove both the capsule and neoplasm. ${ }^{[37]}$ Surprisingly, an abdominal $\mathrm{CT}$ with small bowel follow-through was performed prior to $\mathrm{CE}$, which did not indicate these complications. Up to this point, there have been over 1 million capsules swallowed worldwide and no deaths have been attributed to the capsule itself. ${ }^{[32]}$ If there is a clinical concern for capsule retention, one could try the agile capsule for checking the patency of the intestinal lumen. ${ }^{[38]}$

There were also initial concerns that use of small bowel capsule endoscope may be relatively contraindicated in pediatric patients, patients with dysphagia, or patients with prior altered surgical anatomy. Since the development of a capsule endoscope delivery device, we and others have demonstrated that endoscopic placement of the small bowel PillCAM capsule endoscope can be safely and successfully performed with deployment directly into the small bowel. In most cases, complete small intestinal imaging is achieved and this allows for successful completion of the exam in patients in whom otherwise the procedure would have been contraindicated or is technically challenging ${ }^{[39]}$ [Figure $\left.4 \mathrm{a}-\mathrm{c}\right]$.

\section{Push enteroscopy}

Push enteroscopy (PE) is a type of deep enteroscopy that does not involve the use of a balloon overtube. This modality has the ability to diagnose a cause and provide therapeutic intervention for OGIB, but only to about $50-150 \mathrm{~cm}$ distal to the ligament of Treitz. ${ }^{[3]}$ The diagnostic yield of this procedure is only a modest $24-56 \%,{ }^{[2]}$ but it is still an integral part of patient care in the setting of OGIB. This is especially the case in hospitals that do not have access to the more sophisticated DBE technology. ${ }^{[1]}$ Gómez Rodríguez et al., reported that $121 / 355$ (34\%) patients who had PE were found to have endoscopic lesions. However, only $6 \%$ of these lesions were within the reach of an EGD scope. ${ }^{[40]}$ This shows the great importance of PE in cases where a simple EGD would have missed many lesions distal to the duodenum.
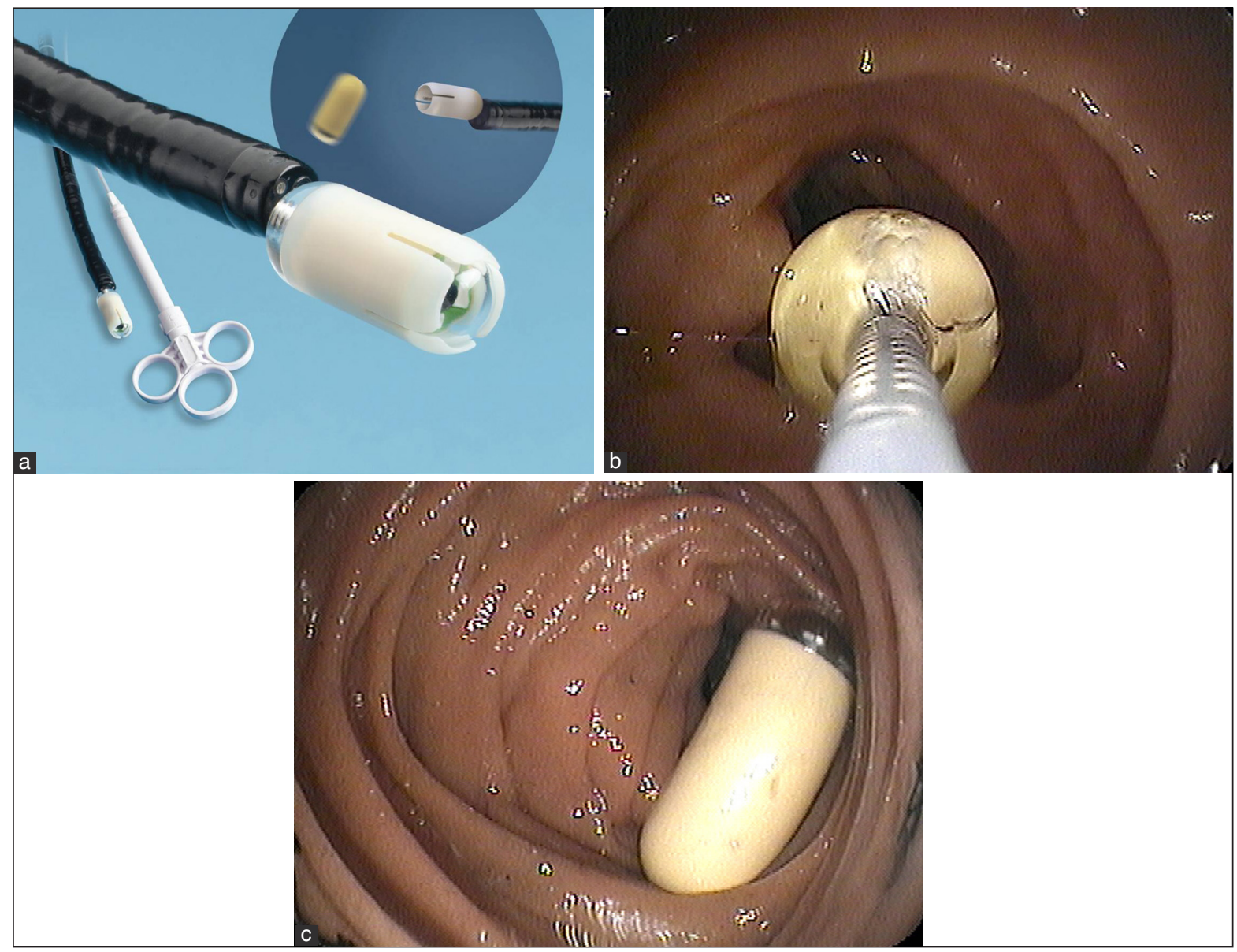

Figure 4: (a) Image of advance delivery device demonstrating the technique of capsule deployment and (b and c) image of the actual capsule deployment in the second portion of the duodenum. This capsule delivery device can be used in cases where problems with swallowing (i.e. in pediatric patients or in patients with dysphagia) may be encountered or in cases of altered surgical anatomy where delivery into the correct intestinal limb is required (image courtesy of (a) US Endoscopy, Mentor, $\mathrm{OH}, \mathrm{USA}$ ) 


\section{Intraoperative enteroscopy}

The modality that was employed in many cases of OGIB was intraoperative enteroscopy (IOE) before many of the technologies available today. This technique involves gaining access to the abdomen via a laparotomy. Once this is completed, an enterotomy is created to allow passage of the scope directly into the small bowel. This procedure can also be done transorally or anally, which avoids the need for an enterotomy. On the contrary, this approach is noted to be time consuming and not as likely to achieve total visualization of the small bowel. ${ }^{[41]}$

IOE has quite a high diagnostic rate, which is between 60 and $88 \%$ for all IOEs performed. ${ }^{[42]}$ This range increases significantly $(83-100 \%)$ if the IOE is being performed after a PE fails to localize a site of bleeding in a patient. ${ }^{[43]}$ In one study, it was found that of 44 patients, $31(70 \%)$ had specific lesions visualized during IOE that were treated during the procedure. Nonetheless, the same study went on to show that the effectiveness of therapy in preventing re-bleeding was only $41 \%$. $^{[44]}$

The role of IOE today is highly selective due to the high morbidity and mortality rates of the procedure compared to other modalities for diagnosing OGIB. Morbidities can include serosal tears, congestive heart failure, and avulsion, to name a few. ${ }^{[45]} \mathrm{In}$ spite of this, it can still be a valuable resource when other methods such as DBE, CE, and radiographic imaging cannot be carried out in a safe manner to the patient or there are contraindicative or inconclusive studies from the other techniques. ${ }^{[1,46]}$

\section{Balloon-assisted deep enteroscopy}

The newest addition to the various modalities of endoscopy field has been the release of the deep "balloon-assisted" enteroscopes. At the forefront of these new technologies are the double balloon enteroscope $^{\mathrm{TM}}$ (Fujinon Inc.) [Figure 5], which has been available for use since 2003, and the single balloon enteroscope ${ }^{\mathrm{TM}}$ (Olympus Inc.) [Figure 6] available since 2007. [3] These revolutionary enteroscopes allow for the visualization of the small bowel through the use of an overtube and balloons to grip the small intestine and

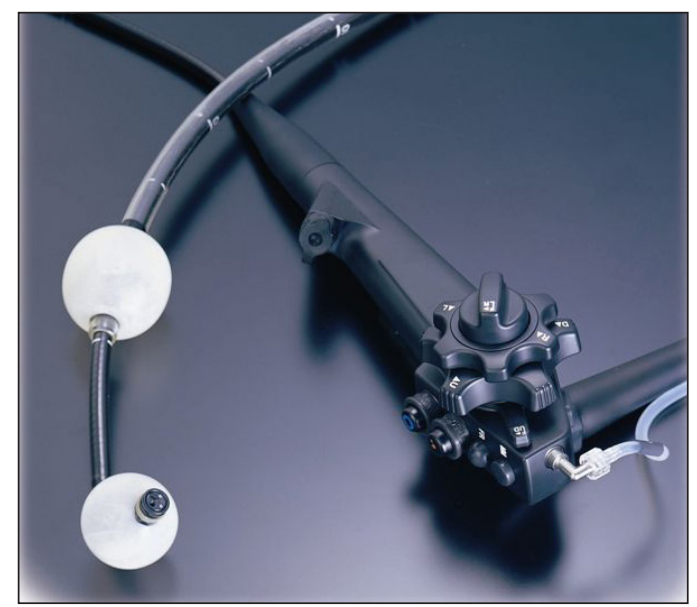

Figure 5: Image of double balloon enteroscope (image provided by FUJIFILM Medical Systems, USA Inc., Endoscopy Division) advance the scope. Each scope is $200 \mathrm{~cm}$ long and has the ability to fully inspect the duodenum, jejunum, and proximal ileum in most cases. Most clinical trials provide data on DBE, but there are only a few select studies that reveal the many technical differences between SBE and DBE, such as procedure time and the rate of total enteroscopy. However, the diagnostic and therapeutic value of these two modalities is still under much scrutiny and only over time can it be clearlys seen which of these two techniques is of better overall quality. One study has found the total enteroscopy rate to be three times greater in DBE than in SBE, ${ }^{[47]}$ while another one has reported the rate to be only about 1.5 times greater. ${ }^{[3]}$ Another study claims the two modalities have similar therapeutic value despite the different rates of total enteroscopy. ${ }^{[48,49]}$ This discrepancy will only be resolved when more of these procedures are done across the globe and more data are collected from these hospitals.

One of the main advantages of DBE over CE is the ability to take biopsies and provide therapeutic intervention [Figure $7 \mathrm{a}$ and $\mathrm{b}$ ]. Using DBE alone, a diagnosis was made $43-80 \%$ of the time and therapy was performed slightly less, being offered to $18-55 \%$ of patients. ${ }^{[50,51]}$ In spite of this, the use of $\mathrm{CE}$ to localize lesions in the small bowel and target them for $\mathrm{DBE}$ shows the intimate relation these two modalities have in diagnosing and treating those with OGIB [Figure 8a and b].

Double balloon endoscopy is extremely labor-intensive with an average procedure time ranging from 73 to $123 \mathrm{~min}^{[50,51]}$ This leads to the fact that DBE has quite a steep learning curve requiring endoscopists to complete at least 10 procedures before seeing a decrease in examination time. ${ }^{[52]}$ Another important aspect to consider is the rate of full enteroscopy using both anterograde and retrograde examination. The rates of completion varied widely between regions, being $70-86 \%$ in Japan while only $4-45 \%$ reported complete enteroscopy in Europe and the United States. ${ }^{[3]}$ There are many variables that account for this discrepancy, such as patient obesity, skill of the endoscopist, and inability to perform a retrograde examination due to poor colon preparation. Other limiting factors of DBE include the use of

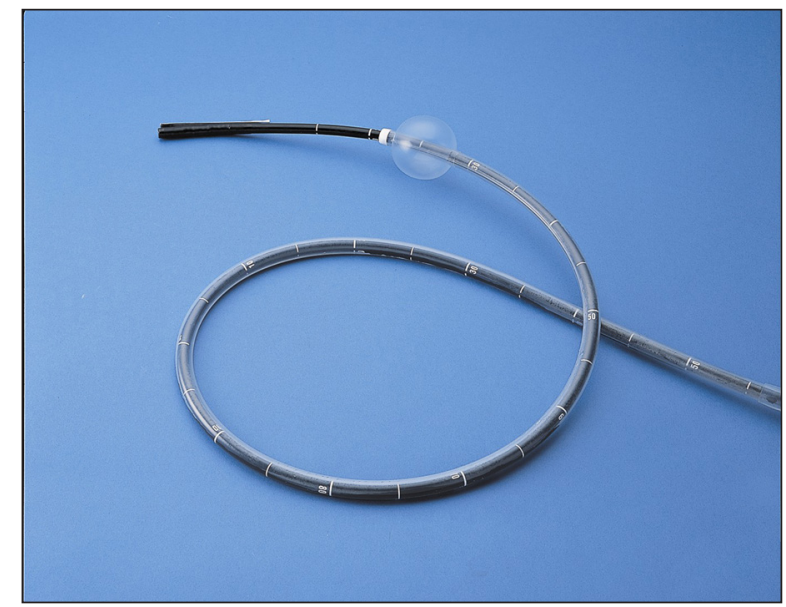

Figure 6: Image of single balloon enteroscope (image courtesy OLYMPUS America, Inc.) 

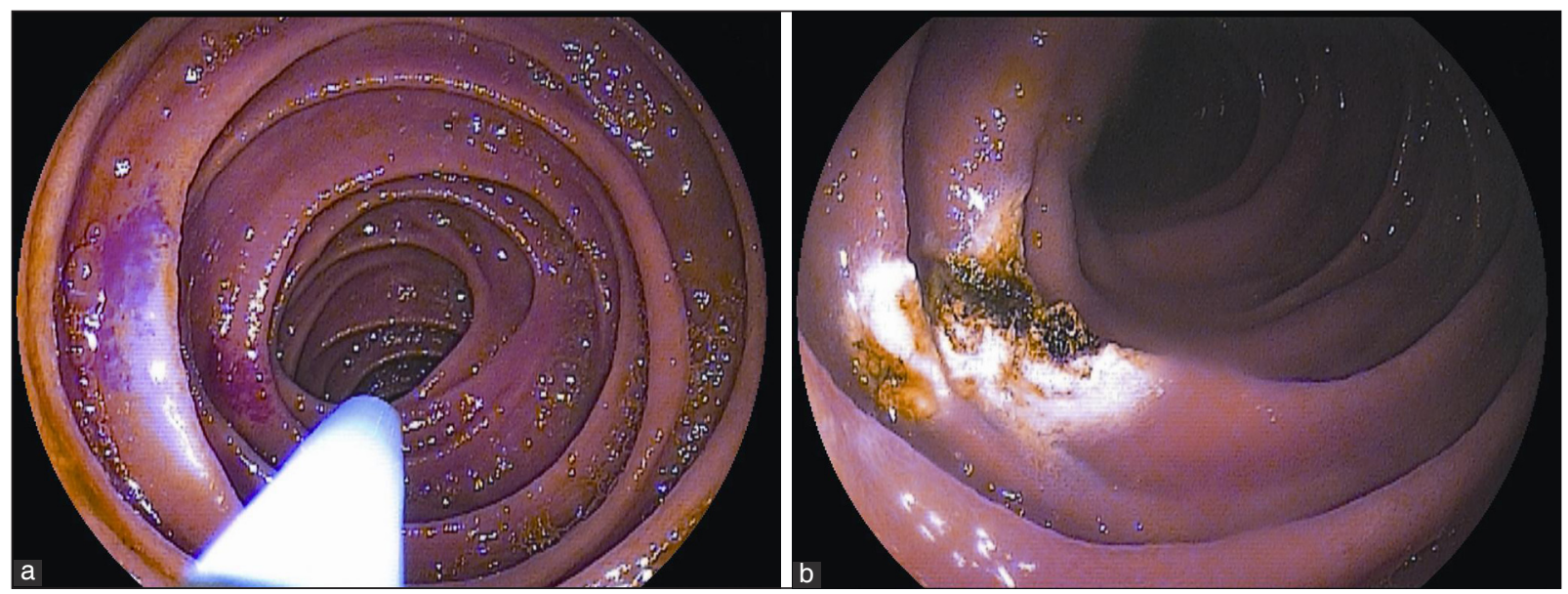

Figure 7: (a, b) Double balloon enteroscopy image of therapy of small bowel arteriovenous malformations (AVMS) seen in the mid/distal jejunum. Therapy performed with argon plasma coagulation
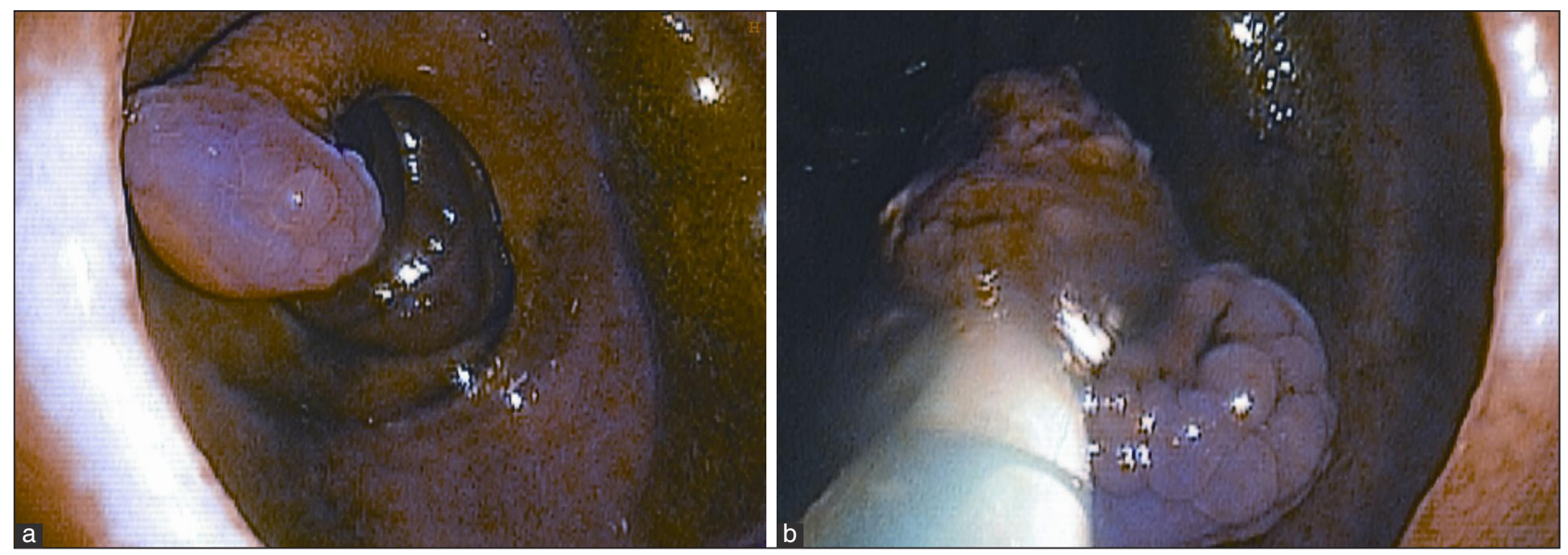

Figure 8: $(a, b)$ Retrograde double balloon enteroscopy performed to evaluate OGIB in a 58-year-old male patient, which diagnosed an ulcerated, inflamed, $1.5 \mathrm{~cm}$ pedunculated mid-ileal polyp. This was removed with snare polypectomy and retrieved. The final pathology was c/w benign, ulcerated inflammatory polyp

general anesthesia and the exclusivity of the technology to certain hospitals. ${ }^{[1]}$ Complications with DBE are very rare and occur in less than $1 \%$ of patients. ${ }^{[53]}$ They usually occur when therapeutic action is taken versus diagnostic ( $4.3 \%$ against $0.8 \%$, respectively, out of 2362 procedures) or the patient has altered surgical anatomy such as an anastomosis. ${ }^{[54]}$ The most common complications are pancreatitis, bleeding, perforation, and aspiration pneumonia. ${ }^{[55]}$

\section{Spiral enteroscopy}

Spiral enteroscopy is another technique of deep enteroscopy. It involves use of an overtube which has grooves, and by rotating the overtube, it pleats the small bowel. The endoscopy can thus be advanced and one can achieve deep intubation of the small bowel. Spiral enteroscopy (Spirus Medical, Inc., Stoughton, MA, USA) has been used for management of small bowel bleeding and performing other diagnostic and therapeutic procedures. The advantage of the system is the rapid deep intubation, thus reducing the procedure time. The main disadvantages are the requirement of two operators - one to rotate the overtube and the other to advance the tube. Also, in a recent prospective cross-over trial, it was noted that the depth of small bowel intubation with spiral enteroscopy was shorter than DBE. ${ }^{[56]}$

\section{Management of - Obscure GI Bleeding}

There are many different approaches to patient care in the setting of OGIB. Physicians have at their disposal a plethora of diagnostic modalities to use, such as CE, DBE, PE, radiographic/nuclear studies, and even surgical intervention. Based on each specific patient, a specific path can be paved to achieve a promising diagnosis and effective therapeutic care can be offered from that point. ${ }^{[49]}$ Here, we provide an algorithm for the assessment and management of OGIB based on whether a patient presents with occult or overt bleeding [Figure 9]. ${ }^{[1,10,19,57,58]}$

In the case of occult bleeding, many patients are given iron therapy and transfusions as an initial treatment in the presence of irondeficiency anemia. For overt bleeding, the first thing to check is whether a patient is actively bleeding. If iron treatment does not 
work or there is no active bleeding, a very common and simple procedure to fall back to is repeating a colonoscopy/EGD (as suggested by our algorithm). While many times this may seem unlikely to yield a cause of bleeding, it is a good way to rule out the possibility of missed lesions due to poor preparation or other complications during the initial procedure..$^{[1]}$

From a purely cost-effective standpoint, proceeding with DBE as the first line of diagnosis is suggested. ${ }^{[7]}$ This is especially the case in high-volume centers where the cost of DBE is significantly lower compared to smaller clinics. ${ }^{[59]}$ However, since CE is usually more tolerable and has the ability to visualize the entire small bowel, it is usually done first before putting a patient through DBE which is a higher-risk and more invasive procedure. ${ }^{[60]}$ In most cases, if a lesion is detected by CE in the mid to distal small bowel, a DBE is required to provide therapy, which is why DBE and CE are thought to be complementary procedures in the investigation of obscure GI bleeding and helping to direct therapy [Figure 10a-c]. ${ }^{[61]}$ Where CE can usually achieve full enteroscopy $83.6 \%$ of the time, it cannot provide biopsies or therapy. ${ }^{[24]}$ On the other hand, DBE can treat lesions directly, but the rate of total enteroscopy is much lower than that of $\mathrm{CE}$; so, there is the chance that lesions can be missed.
Although DBE and CE seem to be able to combat most OGIB causes, the use of other techniques such as IOE and PE should not be overlooked. Lopez et al., found in a study that 14/16 $(88 \%)$ patients were successfully diagnosed using IOE. ${ }^{[62]}$ This technique is invaluable when a patient has gone through countless procedures and there is still no definitive answer to bleeding. ${ }^{[63]}$ Push enteroscopy is much more varied in its diagnostic yield, ranging from 38 to $75 \%$ in several studies. ${ }^{[57]}$ While the range may be wide, this procedure is much less invasive than IOE and is also viable for centers that cannot afford or have no access to DBE.

\section{Conclusion}

Over the course of the past decade, several modalities have been added to the arsenal of gastroenterologists as they continue to combat OGIB. Both $\mathrm{CE}$ and balloon-assisted deep enteroscopy have opened a whole new realm of diagnosis and management of OGIB that was not possible before. Nevertheless, all previous technologies are still viable options in diagnostic and therapeutic regimens for patients because each harbors a unique set of advantages and disadvantages. As endoscopists and GI radiologists

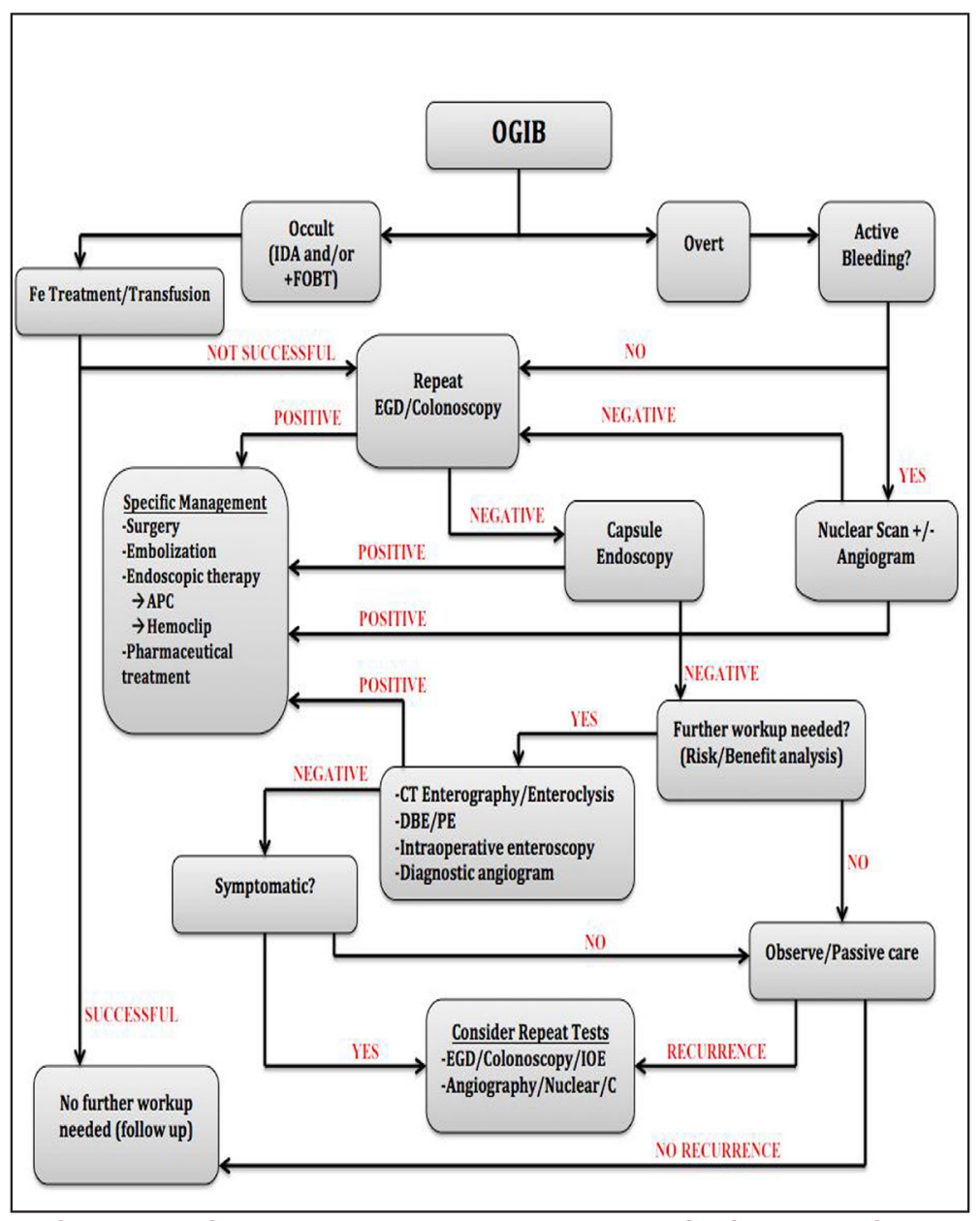

Figure 9: Management algorithm for obscure Gl bleeding based on the International Conference on Capsule Endoscopy (ICCE) consensus guidelines and other recommendations in the published literature ${ }^{[1,38,47,48,63]}$ 

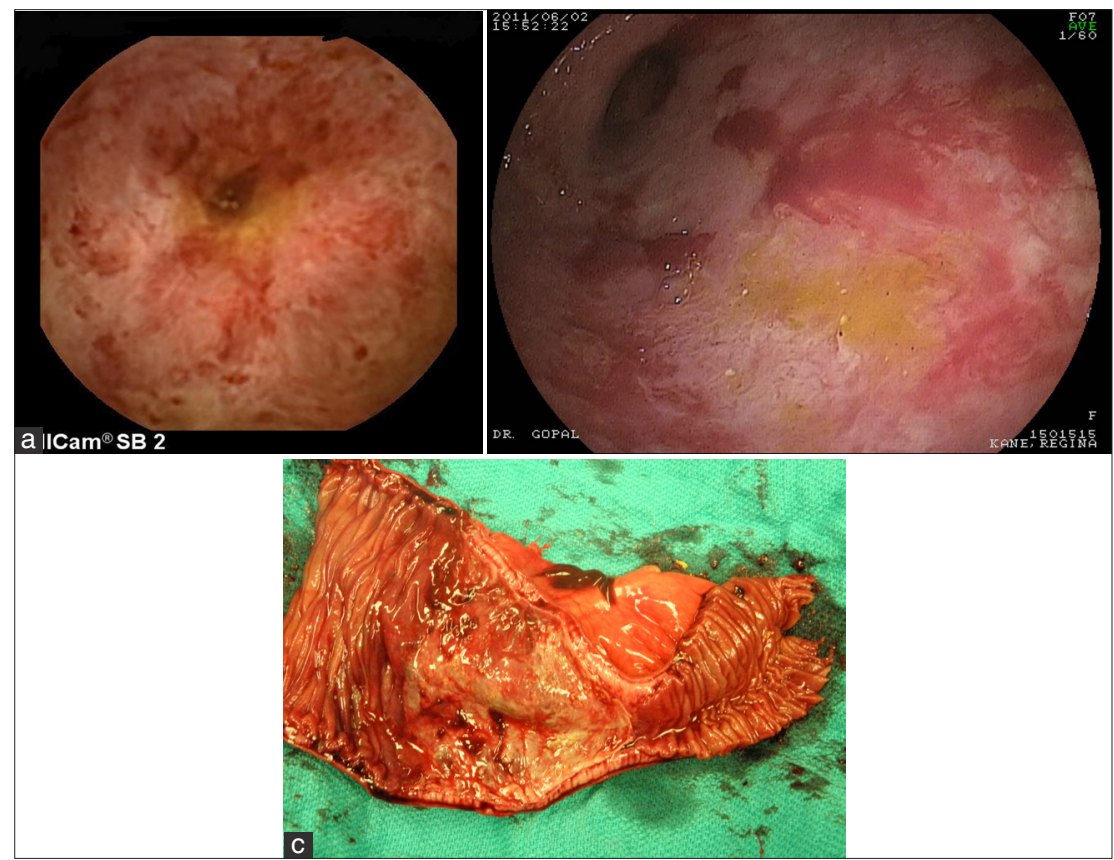

Figure 10: $(a-c)$ Case demonstrating complementary role of CE and DBE. (a) CE image of ulcerated, friable stricture with bleeding in a 54-yearold female who presented for evaluation of OGIB and profound anemia. The DBE exam (b) demonstrates diffuse ulceration with stricture in the distal jejunum/ileum junction and the scope could not be advanced across the stricture. The patient underwent exploratory laparotomy and surgical resection of the involved portion of the small bowel which was identified easily by the tattoo placed at the time of the DBE exam. (c) Surgical resection specimen, and the final pathology was c/w severe, focal ischemic small bowel with stricture

become proficient with these new techniques, they will integrate them with one another and with such a multitude of diagnostic tools. So, hopefully the elusive causes of OGIB will no longer be a mystery to the medical community and patients alike.

\section{REFERENCES}

1. Liu K, Kaffes AJ. Review article: The diagnosis and investigation of obscure gastrointestinal bleeding. Aliment Pharmacol Ther 2011;34:416-23.

2. ASGE Standards of Practice Committee, Fisher L, Lee Krinsky M, Anderson MA, Appalaneni V, Banerjee S, et al. The role of endoscopy in the management of obscure GI bleeding. Gastrointest Endosc 2010;72:471-9.

3. Kita H. Overview of deep small bowel enteroscopy. In: Howell DA, Travis AC, editors. UpToDate. Wolters Kluwer Health. Available from: http:// www.uptodate.com [Last accessed on 2013 Oct 23].

4. Cave D. Evaluation of obscure gastrointestinal bleeding. Saltzman JR, Travis AC Editors. UpToDate. Wolters Kluwer Health. Available from: http://www.uptodate.com [Last accessed on 2013 Nov 20].

5. Goenka MK, Majumder S, Kumar S, Sethy PK, Goenka U. Single center experience of capsule endoscopy in patients with obscure gastrointestinal bleeding. World J Gastroenterol 2011;17;774-8.

6. Graça BM, Freire PA, Brito JB, Ilharco JM, Carvalheiro VM, Caseiro-Alves F. Gastroenterologic and radiologic approach to obscure gastrointestinal bleeding: How, why, and when? Radiographics 2010;30:235-52.

7. Raju GS, Gerson L, Das A, Lewis B, American Gastro-enterological Association. American Gastroenterological Association (AGA) Institute technical review on obscure gastrointestinal bleeding. Gastroenterology 2007;133:1697-717.

8. Rockey DC. Occult gastrointestinal bleeding. Gastroenterol Clin North Am 2005;34:699-718.

9. Dubinsky M. Special issues in pediatric inflammatory bowel disease.
World J Gastroenterol 2008;14:413-20.

10. Huprich JE, Fletcher JG, Alexander JA, Fidler JL, Burton SS, McCullough $\mathrm{CH}$. Obscure Gastrointestinal Bleeding: Evaluation with 64-Section Multiphase CT Enterography - Initial Experience. Radiology 2008;246;562-71.

11. Maglinte DD, Sandrasegaran K, Lappas JC, Chiorean M. CT enteroclysis. Radiology 2007;245:661-71.

12. Huprich JE. Multi-phase CT enterography in obscure GI bleeding. Abdom Imaging 2009;34:303-9.

13. Filippone A, Cianci R, Milano A, Valeriano S, Di Mizio V, Storto ML. Oscure gastrointestinal bleeding and small bowel pathology: Comparison between wireless capsule endoscopy and multidetector-row CT enteroclysis. Abdom Imaging 2008;33:398-406.

14. Hara AK, Walker FB, Silva AC, Leighton JA. Preliminary estimate of triphasic CT enterography performance in hemodynamicallystable patients with suspected gastrointestinal bleeding. AJR Am J Roentgenol 2009;193:1252-60.

15. Zhang BL, Jiang LL, Chen CX, Zhong BS, Li YM. Diagnosis of obscure gastrointestinal hemorrhage with capsule endoscopy in combination with multiple-detector computed tomography. J Gastroenterol Hepatol 2010;25:75-9.

16. Fidler JL, Guimaraes L, Einstein DM. MR imaging of the small bowel. Radiographics 2009;29:1811-25.

17. Schmidt S, Lepori D, Meuwly JY, Duvoisin B, Meuli R, Michetti P, et al. Prospective comparison of MR enteroclysis with multidetector spiralCT enteroclysis: Interobserver agreement and sensitivity by means of "sign-bysign"correlation. Eur Radiol 2003;13:1303-11.

18. Soyer P, Boudiaf M, Fishman EK, Hoeffel C, Dray X, Manfredi $\mathrm{R}$, et al. Imaging of malignant neoplasms of the mesenteric small bowel: New trends and perspectives. Crit Rev Oncol Hematol 2011;80:10-30.

19. Zink SI, Ohki SK, Stein B, Zambuto DA, Rosenberg RJ, Choi JJ, et al. Noninvasive evaluation of active lower gastrointestinal bleeding: Comparison between contrast-enhanced MDCT and 99mTc-labeled RBC scintigraphy. AJR Am J Roentgenol 2008;191:1107-14. 
20. Mariani G, Pauwels EK, AlSharif A, Marchi S, Boni G, Barreca M, et al. Radionuclide evaluation of the lower gastrointestinal tract. J Nucl Med 2008;49:776-87.

21. Wu LM, Xu JR, Yin Y, Qu XH. Usefulness of CT angiography in diagnosing acute gastrointestinal bleeding: A meta-analysis. World J Gastroenterol 2010;16:3957-63.

22. Howarth DM. The role of nuclear medicine in the detection of acute gastrointestinal bleeding. Semin Nucl Med 2006;36:133-46.

23. Nusbaum M, Baum S, Blakemore WS. Clinical experience with the diagnosis and management of gastrointestinal hemorrhage by selective mesenteric catheterization. Ann Surg 1969;170:506-14.

24. Liao Z, Gao R, Xu C, Li ZS. Indications and detection, completion, and retention rates of small-bowel capsule endoscopy: A systematic review. Gastrointest Endosc 2010;71:280-6.

25. Fireman Z, Kopelman Y. The role of video capsule endoscopy in the evaluation of iron deficiency anaemia. Dig Liver Dis 2004;36:97-102.

26. Mazzarolo S, Brady P. Small bowel capsule endoscopy: A systematic review. South Med J 2007;100:274-80.

27. Bresci G, Parisi G, Bertoni M, Tumino E, Capria A. The role of video capsule endoscopy for evaluating obscure gastrointestinal bleeding: Usefulness of early use. J Gastroenterol 2005;40:256-9.

28. May A, Wardak A, Nachbar L, Remke S, Ell C. Influence of patient selection on the outcome of capsule endoscopy in patients with chronic gastrointestinal bleeding. J Clin Gastroenterol 2005;39:684-8.

29. Thomson M, Venkatesh K, Elmalik K, van der Veer W, Jaacobs M. Double balloon enteroscopy in children: Diagnosis, treatment, and safety. World J Gastroenterol 2010;16:56-62.

30. van Gossum A, Francois E, Hittelet A, Schmit A, Devière J, et al. A prospective comparative study between push-enteroscopy and wireless video capsule in patients with obscure digestive bleeding. Gastroenterology 2003;125:276.

31. Liangpunsakul S, Chadalawada V, Rex DK, Maglinte D, Lappas J. Wireless capsule endoscopy detects small bowel ulcers in patients with normal results from state of the art enteroclysis. Am J Gastroenterol 2003;98:1295-8.

32. Cave D. Wireless video capsule endoscopy. In: Saltzman JR, Travis AC, editors. UpToDate. Wolters Kluwer Health. Available from: http://www. uptodate.com [Last accessed on 2013 Oct 30].

33. Scapa E, Jacob H, Lewkowicz S, Migdal M, Gat D, Gluckhovski A, et al. Initial experience of wireless-capsule endoscopy for evaluating occult gastrointestinal bleeding and suspected small bowel pathology. Am J Gastroenterol 2002;97:2776-9.

34. Cheifetz AS, Kornbluth AA, Legnani P, Schmelkin I, Brown A, Lichtiger $\mathrm{S}$, et al. The risk of retention of the capsule endoscope in patients with known or suspected Crohn's disease. Am J Gastroenterol 2006;101:2218-22.

35. Chak A, Koehler MK, Sundaram SN, Cooper GS, Canto MI, Sivak MV Jr. Diagnostic and therapeutic impact of push enteroscopy: Analysis of factors associated with positive findings. Gastrointest Endosc 1998;47:18-22.

36. Bandorski D, Keuchel M, Brück M, Hoeltgen R, Wieczorek M, Jakobs R. Capsule endoscopy in patients with cardiac pacemakers, implantable cardioverter defibrillators, and left heart devices: A review of the current literature. Diagn Ther Endosc 2011;2011:376053.

37. Katsinelos P, Kountouras J, Chatzimavroudis G, Zavos C, Pilpilidis I, Fasoulas K, et al. Wireless capsule endoscopy in detecting small-intestinal polyps in familial adenomatous polyposis. World J Gastroenterol 2009;15:6075-9.

38. Herrerias JM, Leighton JA, Costamagna G, Infantolino A, Eliakim R, Fischer D, et al. Agile patency system eliminates risk of capsule retention in patients with known intestinal strictures who undergo capsule endoscopy. Gastrointest Endosc 2008;67:902-9.

39. Holden JP, Dureja P, Pfau PR, Schwartz DC, Reichelderfer M, Judd RH, et al. Endoscopic placement of the small-bowel video capsule by using a capsule endoscope delivery device. Gastrointest Endosc 2007;65:842-7.

40. Gómez Rodríguez BJ, Ortiz Moyano C, Romero Castro R, Caunedo Alvarez A, Hernández Durán MD, Hergueta Delgado P, et al. Diagnostic yield of 335 push video-enteroscopies. Rev Esp Enferm Dig 2006;98:8292.

41. Schulz HJ, Schmidt H. Intraoperative enteroscopy. Gastrointest Endosc Clin N Am 2009;19:371-9.

42. Raju GS, Gerson L, Das A, Lewis B, American Gastroenterological Association. American Gastroenterological Association (AGA) Institute medical position statement on obscure gastrointestinal bleeding. Gastroenterology 2007;133:1694-6.

43. Ghosh S, Watts D, Kinnear M. Management of gastrointestinal haemorrhage. Postgrad Med J 2002;78:4-14.

44. Pérez Roldán F, González Carro P, Legaz Huidobro ML, Roncero GarcíaEscribano O, Ynfante Ferrús M, Aoufi S, et al. Efficacy of pediatric colonoscopy used as push enteroscopy in the management of capsule endoscopy findings. Rev Esp Enferm Dig 2009;101:468-76.

45. Ress AM, Benacci JC, Sarr MG. Efficacy of intraoperative enteroscopy in diagnosis and prevention of recurrent, occult gastrointestinal bleeding. Am J Surg 1992;163:94-8.

46. Bowden TA Jr, Hooks VH 3rd, Mansberger AR Jr. Intraoperative gastrointestinal endoscopy. Ann Surg 1980;191:680-7.

47. May A, Färber M, Aschmoneit I, Pohl J, Manner H, Lotterer E, et al. Prospective multicenter trial comparing push-and-pull enteroscopy with the single- and double-balloon techniques in patients with small-bowel disorders. Am J Gastroenterol 2010;105:575-81.

48. Moreels TG, Pelckmans PA. Comparison between double-balloon and single-balloon enteroscopy in therapeutic ERC after Roux-en-Y enteroenteric anastomosis. World J Gastrointest Endosc 2010;2:314-7.

49. Raju GS, Gerson L, Das A, Lewis B. American Gastro-enterological Association (AGA) Institute medical position statement on obscure gastrointestinal bleeding. Gastroenterology 2007;133:1694-96.

50. Yamamoto H, Kita H, Sunada K, Hayashi Y, Sato H, Yano T, et al. Clinical outcomes of double-balloon endoscopy for the diagnosis and treatment of small-intestinal diseases. Clin Gastroenterol Hepatol 2004;2:1010-6.

51. Ell C, May A, Nachbar L, Cellier C, Landi B, di Caro S, et al. Push-and-pull enteroscopy in the small bowel using the double-balloon technique: Results of a prospective European multicenter study. Endoscopy 2005;37:613-6.

52. Gerson LB, Batenic MA, Newsom SL, Ross A, Semrad CE. Long-term outcomes after double-balloon enteroscopy for obscure gastrointestinal bleeding. Clin Gastroenterol Hepatol 2009;7:664-9.

53. Mensink PB, Haringsma J, Kucharzik T, Cellier C, Pérez-Cuadrado E, Mönkemüller K, et al. Complications of double balloon enteroscopy: A multicenter survey. Endoscopy 2007;39:613-5.

54. Pasha SF, Leighton JA, Das A, Harrison ME, Decker GA, Fleischer $\mathrm{DE}$, et al. Double-balloon enteroscopy and capsule endoscopy have comparable diagnostic yield in small-bowel disease: A meta-analysis. Clin Gastroenterol Hepatol 2008;6:671-6.

55. Mehdizadeh S, Han NJ, Cheng DW, Chen GC, Lo SK, et al. Success rate of retrograde double-balloon enteroscopy. Gastrointest Endosc 2007;65:633-9.

56. May A, Manner H, Aschmoneit I, Ell C. Prospective, cross-over, single-center trial comparing oral double-balloon enteroscopy and oral spiralenteroscopy in patients with suspected small-bowel vascular malformations. Endoscopy 2011;43:477-83.

57. Amaro R, Barkin JS. Diagnostic and therapeutic options in obscure gastrointestinal blood loss. Curr Gastroenterol Rep 2000;2:395-8.

58. Mergener K, Ponchon T, Gralnek I, Pennazio M, Gay G, Selby W, et al. Literature review and recommendations for clinical application of smallbowel capsule endoscopy, based on a panel discussion by international experts. Consensus statements for small-bowel capsule endoscopy, 2006/2007. Endoscopy 2007;39:895-909.

59. Albert JG, Nachtigall F, Wiedbrauck F, Dollinger MM, Gittinger FS, Hollerbach S, et al. Minimizing procedural cost in diagnosing small bowel bleeding: Comparison of a strategy on initial capsule endoscopy versus initial double-balloon enteroscopy. Eur J Gastroenterol Hepatol 2010;22:679-88.

60. Westerhof J, Weersma RK, Koornstra JJ. Investigating obscure gastrointestinal bleeding: Capsule endoscopy or double balloon enteroscopy? Neth J Med 2009;67:260-5.

61. Bar-Meir S. Video capsule endoscopy or double-balloon enteroscopy: Are they equivalent? Gastrointest Endosc 2009;69:875-6. 
62. Lopez MJ, Cooley JS, Petros JG, Sullivan JG, Cave DR. Complete intraoperative small-bowel endoscopy in the evaluation of occult gastrointestinal bleeding using the Sonde enteroscope. Arch Surg 1996;131:272-7.

63. Goldfarb NI, Phillips A, Conn M, Lewis BS, Nash DB. Economic and health outcomes of capsule endoscopy: Opportunities for improved management of the diagnostic process for obscure gastrointestinal bleeding. School of Population Health Faculty Papers. Dis Manage 2002;5:123-35.

How to cite this article: Prabakaran P, Guda N, Thomas J, Heise C Gopal D. Clinical approach to obscure GI bleeding - Diagnostic testing and management. J Dig Endosc 2013;4:61-76.

Source of Support: Nil, Conflict of Interest: None declared.

\section{Author Help: Online submission of the manuscripts}

Articles can be submitted online from http://www.journalonweb.com. For online submission, the articles should be prepared in two files (first page file and article file). Images should be submitted separately.

1) First Page File:

Prepare the title page, covering letter, acknowledgement etc. using a word processor program. All information related to your identity should be included here. Use text/rtt/doc/pdf files. Do not zip the files.

2) Article File:

The main text of the article, beginning with the Abstract to References (including tables) should be in this file. Do not include any information (such as acknowledgement, your names in page headers etc.) in this file. Use text/rtf/doc/pdf files. Do not zip the files. Limit the file size to $1 \mathrm{MB}$. Do not incorporate images in the file. If file size is large, graphs can be submitted separately as images, without their being incorporated in the article file. This will reduce the size of the file.

3) Images:

Submit good quality color images. Each image should be less than 4 MB in size. The size of the image can be reduced by decreasing the actual height and width of the images (keep up to about 6 inches and up to about $1800 \times 1200$ pixels). JPEG is the most suitable file format. The image quality should be good enough to judge the scientific value of the image. For the purpose of printing, always retain a good quality, high resolution image. This high resolution image should be sent to the editorial office at the time of sending a revised article.

4) Legends:

Legends for the figures/images should be included at the end of the article file. 